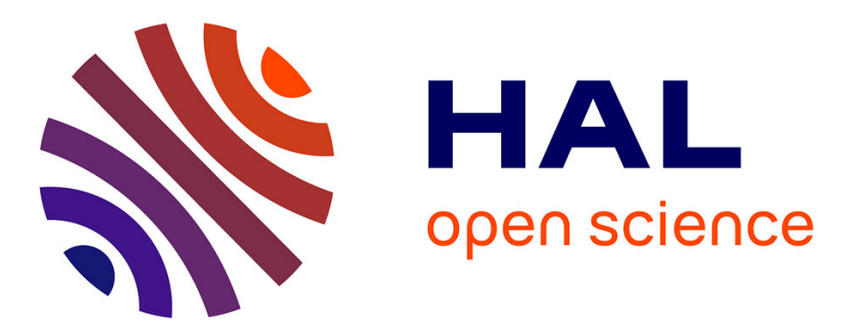

\title{
Structural transition of polyethylene oxide networks studied by positron annihilation
}

\author{
Biao Wang, Z. Peng, Y. Dai, S. Li, S. Wang, Hong Liu, H. Xie
}

\section{To cite this version:}

Biao Wang, Z. Peng, Y. Dai, S. Li, S. Wang, et al.. Structural transition of polyethylene oxide networks studied by positron annihilation. Journal de Physique IV Proceedings, 1993, 03 (C4), pp.C4-257-C4260. 10.1051/jp4:1993439. jpa-00251482

\section{HAL Id: jpa-00251482 https://hal.science/jpa-00251482}

Submitted on 1 Jan 1993

HAL is a multi-disciplinary open access archive for the deposit and dissemination of scientific research documents, whether they are published or not. The documents may come from teaching and research institutions in France or abroad, or from public or private research centers.
L'archive ouverte pluridisciplinaire HAL, est destinée au dépôt et à la diffusion de documents scientifiques de niveau recherche, publiés ou non, émanant des établissements d'enseignement et de recherche français ou étrangers, des laboratoires publics ou privés. 


\title{
Structural transition of polyethylene oxide networks studied by positron annihilation
}

\author{
B. WANG, Z.L. PENG, Y.Q. DAI, S.Q. LI, S.J. WANG, H. LIU* and H.Q. XIE*
}

Department of Physics, Wuhan University, Wuhan 430072, P.R. of China

* Department of Chemistry, University Huazhong of Sci. \& Tech., Wuhan 430074, P.R. of China

\begin{abstract}
Positron lifetime spectra have been measured for network polyethylene oxide (PEO) in the temperature range of $120-345 \mathrm{~K}$. The glass transition and secondary structural transition have been observed and the transition temperatures were determined. The changes of free-volume in amorphous regions and the defect properties in crystalline are discussed.
\end{abstract}

\section{Introduction}

The discovery of conductivity in polyethylene oxide ( PEO)-salt complexes has led to an extensive interest to researchers. However, the main disadvantage of using high molecular weight $P E O$ is the high crystallinity, which reduces the ionic conductivity. Attempts to increase ionic conductivity by lowering the molecular weight or the glass transitiontmake the mechanical properties inferior. Therefore, it is very important to find a polymer which has both high ionic conductivity and good mechanical properties. In fact, recent studies have focused attention on the use of polyethylene oxide-containing block copolymers, comb polymers, crosslinked polymers, polymer blends and interpenetrating polymer networks [1] to replace the high molecular weight PEO, so as to obtain the suitable properties of chemistry and physics. In addition the ionic conductivity mainly takes place in the amorphous phase[2], so the study of relation between ionic conductivity and free-volume and the properties of free volume are very interesting.

In this paper, the structural transition of crosslinking PEO has been studied by positron annihilation parameters versus temperature.

\section{EXPERTMRNT}

The network structure of PEO (the molecular weight is 1540 ) was prepared by slight crosslinking with trimethylol propane (TMP) after mixing of PEO and tolylene diisocyanate(TDI). A $40{ }_{\mu} \mathrm{C}_{\mathrm{i}}{ }^{24} \mathrm{Na}$ positron source was placed between two discs of the same samples. Positron 
lifetime measurements were performed using a fast- fast coincidente system which hag a time resolution of 245 from the prompt curve of a "Co source. A million counts vere collected for each spectrum in about 60 minutes.

\section{RESULTS and DISCUSSTON}

All lifetime spectra measured have been well resolved into three lifetime components using the computer program [3] after source correction. The variations of positron annihilation parameters versus temperature $(120-345 \mathrm{~K})$ are shown in figures $1-4$.

\section{Free-volume properties}

As shown in figure 1 and 2 , the changes of the longest component $\tau_{3}$ and $I_{3}$ demonstrate a significant temperature dependence. The glass transition temperature $T_{\vec{g}}$ and $P E O$ chains melt temperature lexcluding

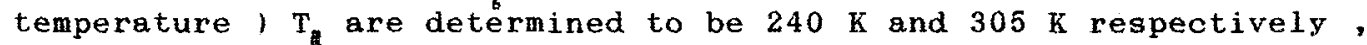
as shown in figure 1 , which are consistent with differential scanning calorimetry (DSC) [4] and also be observed in other polymers [5]. Between $T_{g}$ and $T_{a}$, the size and concentration of free volume increase steeply. It can be explained as follows, when the temperature increases the long chain segments and molecules all participate in motion owing to themal activation $(i . e .$, the micro-Brownian motion increases), which leads to increase of $I_{3}$. At the same time, the higher the temperature, the easier the free volume thermal expansion, which results in the drastic increase of $\tau_{3}$. After reaching the $T_{1}$, $\tau_{3}$ and $I_{3}$ increase slowly. Because the rubbery turnsinto a real- liquid state, so that the polymer molecules have a relaxation comparable with o-Ps lifetime and a Ps bubble can be formed by Ps, lead to the variation of $I_{3}$ and $\tau_{3}$ not to crucially depend on the expansion of free volume $[5-6]$.

The secondary relaxation at $130 \mathrm{~K}$ has also been observed besides $T_{0}$

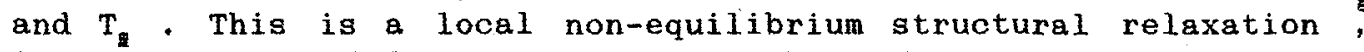
i.e, time effect [6], because the annealing time of the specimen from room temperature to $120 \mathrm{~K}$ before measurement is not long enough for PEO to reach its equilibrium state. Perhaps, it results from crankshaft motion and interior rotation of methvl in benzene $r i n g$. Between 150 and $240 \mathrm{~K}$, the size of free volume does not change nearly , but the concentration of free volume holes inereases, which indicates that the increase of the local changes motion with increase of temperature mainly gives rise to free volume holes increase. As far as we know, it has not been reported about secondary relaxation.

\section{Microstructural changes in crystalline regions}

The microstructural changes in crystalline regions is more complex than in amorphous areas. It is clear that crystalline polymers are by no means perfect from a structural viewpoint. The defects which have been found to exist or postulated are as follows: point defects, dislocations and other defects... [7]. The mechanism of relaxation behavior of semi-crystalline polymers is not very clear. The 
relaxation behavior of polyethylene has probably been more widely studied than that any other semi-crystalline polymers, even though it is not completely understood so far [7]. So the relaxation behavior of crrstalline regions is much complex. As far as we know, there are not reports about the relaxation behavior of $\mathrm{PEO}$.

According to Authors of $[8-10]$, we think that the positron annihilation chiefly takes place in crystalline regions, so the positron annihilation parameters $t_{2}$ and $I_{2}$ give direct information to the relaxation of crystalline regions.

The microstructural changes in crystalline regions can be analyzed in terms of $\tau_{\hat{q}}$ and $I_{q}$ of intermediate lifetime component versus the temperature. As shown in figures 3 and $4, I_{2}$ shows a similar temperature dependence to $t_{3}$ with the exception of initial temperature ranges $(120-140 \mathrm{~K})$. A peak of $t_{2}$ and vallev of $I_{2}$ at $130 \mathrm{~K}$ are observed, this is a $\gamma$ relaxation in crystalline regions. It is thought that the $\gamma$-peak may associated with the local motion of defects [11], such as chain ends, point defects and edge dislocations. They bring about the variations of $\tau_{\hat{q}}$ and $I_{q}$. It is very interesting to observe the $\alpha$ relaxation near $T_{g}$. It perhaps results from both the motion of folding chains in lamella and twisting of stretching chains. $T_{g}$ is maybe a phase transition point of crystalline region. Above $\mathrm{T}_{\mathrm{g}}, \mathrm{I}_{\hat{q}}$ increases with increases of temperature, but $\tau_{\varepsilon}$ continuously diminishes, which indicates that the motion of defects owing to thermal activation mainly bring about increase of concentration of their.

Fig.1 The plot of o-Ps lifetime $\tau_{3}$ vs temperature for $\mathrm{PEO}$

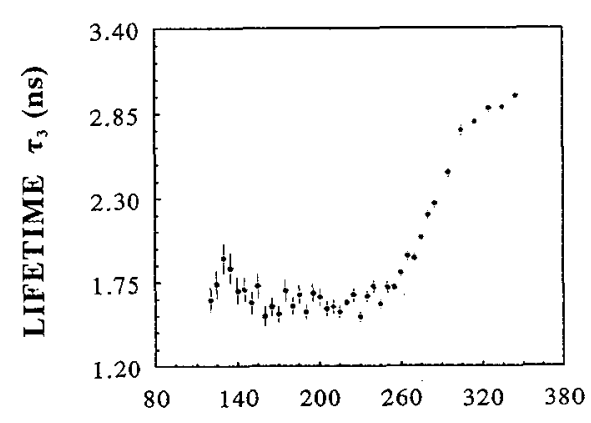

$\mathbf{T}(\mathbf{K})$
Fig.2 The plot of o-Ps intensity $I_{3}$ vs temperature for PEO

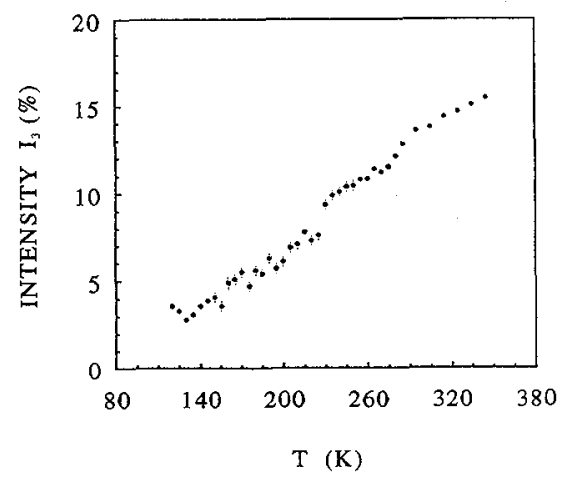


Fig. 3 The plot of positron lifetime $\tau_{i}$ vs temperature for PEO

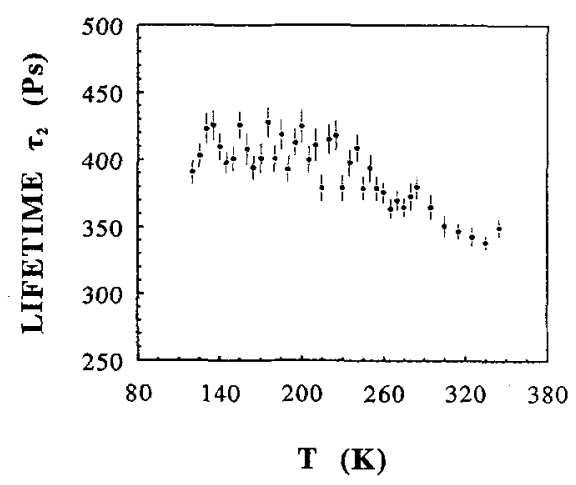

Fig. 4 The plot of positron intensity $I_{\hat{q}}$ vs temperature for PEO

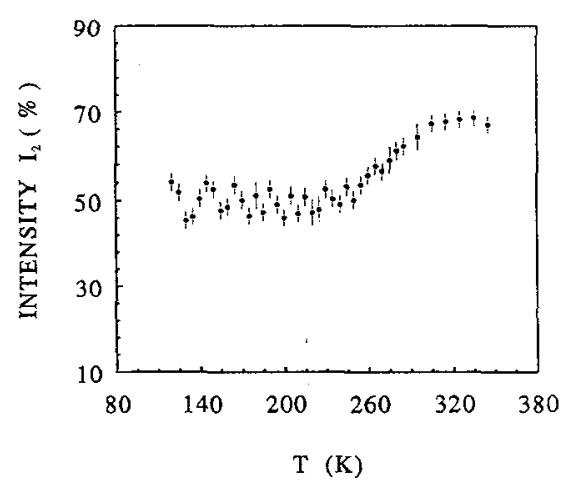

\section{RREFKRWNCES}

/1/ N Yak, acromol. Sci-phys, B 30 (3), (1991) 225-243

/2/ M mincer, C Berthier, W Gorecki, J. phys, 45 (1984) 739

/3/ P Kirkegard, M Eldrup, O Mogensen and N Petersen, Comp.phys.Commun 23 (1981) 307

/4/ Watanabe Masayoshi, Itoh Masashi, Sanui Kohei and Ogat Naoya, Macromolecules 20 (1987) 569-573

/5/ Y C Jean Microchen J, 42 (1990) 72

/6/ D lin and S J Wang, J. Phys, Condensed Matter 4 (1992) 3331-3336

17/ Young Robert J, "Introduction to Polymers ", (1981) London

18/ A V Goldanskii, V A Onishuk, and V P SHantarovich, Phys. Stat. Sol . (a) $102(1987) 559$

19/ A Chandrashekara , V Sreeramalu, H R Sreepad, V Ravindrachary, C Ranganathaiah, and S Gopal, Phys . Stat. Sol. (a) 125 (1991) 509

/10/ PKindl and G Reiter, Phys . Stat. Sol, (a). 104 (1987) 707

/11/ I M Ward, "Mechanical Properties of Solid Polymers", Wibey-Interscience, 2nd. Ed 